\title{
The Thebesian valve and its significance for electrophysiologists
}

\author{
M. Mazur ${ }^{1}$, R. Tomaszewska², A. Pasternak¹, M. Kuniewicz ${ }^{1}$, J.A. Walocha ${ }^{1}$ \\ ${ }^{1}$ Department of Anatomy, Jagiellonian University Medical College, Krakow, Poland \\ ${ }^{2}$ Department of Pathomorphology, Jagiellonian University Medical College, Krakow, Poland
}

[Received 10 February 2014; Accepted 25 March 2014]

\begin{abstract}
Background: Invasive cardiac procedures, such as arrhythmia ablation, cardiac resynchronisation therapy, percutaneous mitral annuloplasty and retrograde cardioplegia delivery require cannulation of the coronary sinus (CS). Detailed knowledge of the CS ostium region, including recognition of the presence of the Thebesian valve which sometimes covers the sinus, is a key to successfully carry out such procedures.

Materials and methods: In the present study, 160 autopsied human hearts from both sexes were examined for the presence of the Thebesian valve. If identified, the histological structure of the valve was studied.

Results: Five types of the CS valve were distinguished; all of them presented with a typical histological structure with the exception of the cord-like type, in which cells were similar to those of the conduction system of the heart.

Conclusions: Proper identification of the CS valve and analysis of its size and histological features could have important implications for electrophysiologists. (Folia Morphol 2014; 73, 3: 298-301)
\end{abstract}

Key words: Thebesian valve, coronary sinus valve, conduction system of the heart

\section{INTRODUCTION}

The coronary sinus (CS) is the main venous vessel of the heart, receiving about $60 \%$ of the blood returning to the right atrium. It is located in the posterior part of the coronary groove, between the left ventricle and the left atrium. The ostium of this sinus is situated in the angle between the inferior and medial walls of the right atrium and above the opening for the inferior vena cava. Sometimes the opening of the CS is guarded by a valve of variable morphology and size, known as the Thebesian valve, which is a remnant of the right valve of the venous sinus [9, $15,16]$. There is a great deal of variability within the coronary venous system that usually does not have any clinical importance. However, in procedures such as arrhythmia ablation, cardiac resynchronisation the- rapy (CRT) and cardioplegia delivery, variability in this region may contribute to the difficulties that can be encountered during CS cannulation. The development of effective and dynamic invasive cardiology requires detailed descriptions of this region and appraisal of the clinical significance of its morphology $[4,5,10$, 14]. Thus, the aim of this study was to examine the correlation between the structure of the Thebesian valve and unsuccessful CS cannulation.

\section{MATERIALS AND METHODS}

The research was conducted on 160 autopsied human hearts from both sexes, aged 17-70. Eighty three per cent of specimens were from male cadavers while $17 \%$ were obtained from female cadavers. The study protocol was approved by the local ethics committee

Address for correspondence: M. Mazur, MD, PhD, Department of Anatomy, Jagiellonian University Medical College, ul. Kopernika 12, 31-034 Kraków, Poland, tel/fax: +48 1242295 11, e-mail: malg.mazur@uj.edu.pl 
were examined. Classic anatomical techniques were performed. To uncover the region of CS ostium, an incision was made from the right auricle to the superior vena cava opening. Presence and morphology of the Thebesian valve was noted and documented photographically. The CS valves were dissected and used in histological preparations. Tissues samples of $1 \mathrm{~cm} \times 1 \mathrm{~cm}$ were taken and preserved in 10\% formalin solution before being hardened in paraffin. Subsequently histological preparations were sliced longitudinally and stained in haematoxylin-eosin solution in Masson's modification. All preparations were microscopically examined and documented photographically.

\section{RESULTS}

A well-developed CS was observed in all the hearts with the ostium extending into the right atrium. Within the ostium, on the right side of its circumference, a variably developed Thebesian valve was found. In 36 (22.5\%) specimens the valve was absent. Five types of the Thebesian valve were distinguished based on morphology. Absence of the CS valve was classified as type I. Type II looked like a cord or strand, sometimes dividing the orifice into two parts. Type III was composed of a very small rudimentary piece of endocardium. In some hearts, the Thebesian valve was well-developed and semilunar in shape; this was classified as type IV. Lastly, type V valves were big, usually covered the ostium, and resembled a fold. The semilunar valve (type IV) was the most frequently observed morphology of the Thebesian valve observed in $27.5 \%$ of hearts. The least common conformations were the type II strands which were found in only $12.5 \%$ of specimens. All histological preparations obtained from types III, IV and V revealed a structure typical for the CS valve: a surface lined with endocardium, collagen and elastic fibres, and myocardial cells (Fig. 1). In type II strand valves, cells rich in sarcoplasm with big dark staining nuclei were observed (Figs. 2, 3). These cells resembled those of conduction system of the heart.

\section{DISCUSSION}

Development of invasive cardiac procedures led electrophysiologists to focus more attention on the anatomy of the CS ostium, especially the opening into the right atrium. Access to the CS via its orifice is essential in CRT, electrophysiological study, cardiovascular angiographic analysis, and percutaneous mitral annuloplasty $[6,17]$. Clinicians are challenged by the

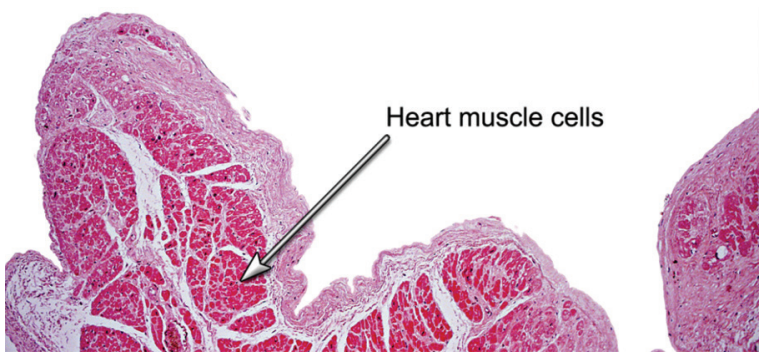

Figure 1. Typical histological structure of the coronary sinus valve stained in haematoxylin-eosin solution.

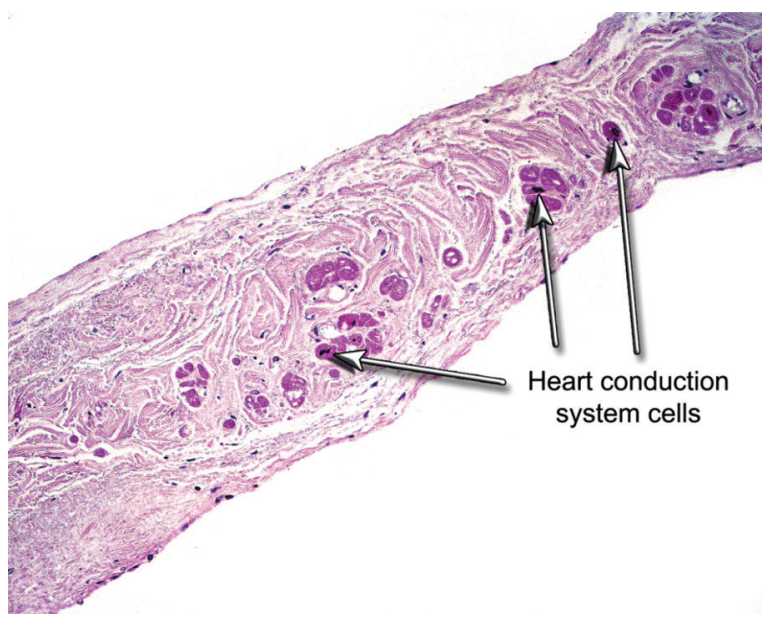

Figure 2. Histological structure of the strand-like valve stained in haematoxylin-eosin solution.

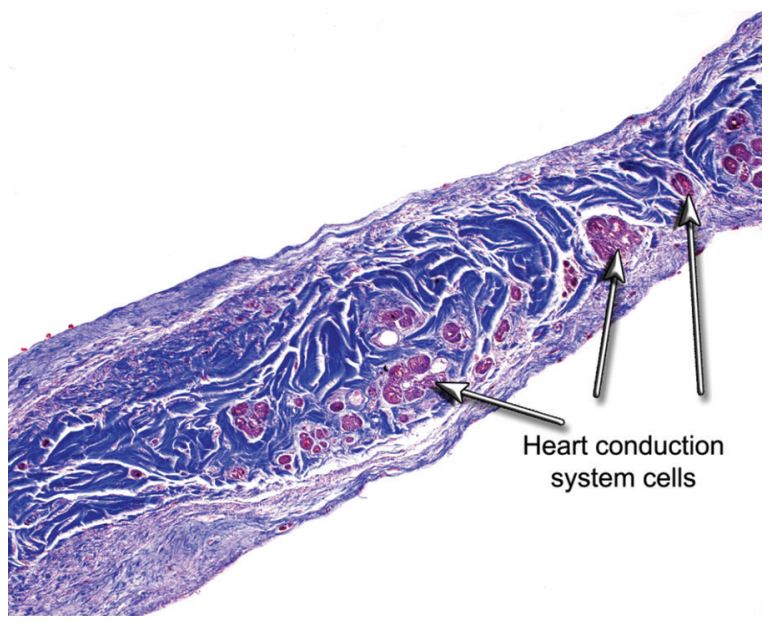

Figure 3. Histological structure of the strand-like valve stained in haematoxylin-eosin solution in Masson's modification.

No. KBET\40|B\2007. Only hearts without any defects or macroscopically visible pathology from individuals whose cause of death was not cardiological in nature 
great variability in the morphology of the coronary venous system such as the localisation, angulation and diameter of the CS ostium, as well as the presence of Thebesian valve which can complicate or inhibit sinus cannulation. Anatomists and clinicians have tried to describe this region in a manner which would be useful for electrophysiologists.

In the present investigation, the presence of Thebesian valve was observed in $77.5 \%$ of hearts, which is similar to previous studies. The Thebesian valve has been identified in a significant number of hearts examined by various researchers $[2,8]$. In their study on 54 hearts obtained from patients with atherosclerosis, cardiomyopathy, left ventricular enlargement and endocarditis, Mak et al. [11] observed the CS valve in $73 \%$ of specimens. Meanwhile, Pejkovic et al. [15] identified the Thebesian valve in $80 \%$ of their sample.

The morphology of the cardiac sinus region in the current examination revealed several types of Thebesian valves which differed in conformation as well as in the proportion of ostium they covered. Type $V$ Thebesian valves were rather large and usually spanned a sizeable portion of the ostium. Tissues samples from the different valve types were fairly similar histologically with the exception of type II valves which contained cells with features similar to the conduction system of the heart. Katti and Patil [8] examined 50 autopsied hearts and observed great variability in the Thebesian valve, noting that in $20 \%$ of specimens it covered more than $60 \%$ of the ostium. They also examined the histological structure of the valves confirming its typical components: endocardium with collagen and muscular fibres [8].

The clinical implications of the topography of the CS region are not yet fully understood $[1,7,12$, $13,16]$. Of the patients undergoing invasive cardiac procedures, CS cannulation is unsuccessful in $5-10 \%$ of individuals, although Mak et al. [11] believe that the incidence is underreported. Cao et al. [3] reported a case of complicated implantable cardioverter-defibrillator procedure caused by a prominent Thebesian valve that required that implantation be made using an alternative venous approach due to the obstruction caused by the valve. Anh et al. [2] visually examined the CS of 98 individuals during pacemaker implantation and observed a Thebesian valve in $54 \%$ of patients, with $6 \%$ of these having an ostium that was more than $70 \%$ covered by a huge valve. To address this complication, direct visualisa- tion and modern catheterisation techniques were employed allowing successful implantation to occur despite the obstruction provided by the large valve. Therefore visualisation and a clear understanding of the CS ostium morphology can improve the success rate of CS cannulation.

Potentially complicating features of the Thebesian valve include atypical histological features and large valve size, as observed in type $V$ valves, which has the ability to occlude the venous sinus. Difficulties in advancing the catheter during cannulation of the CS may be due to atypical histological structure of the valves, represented by the strand type valve [6]. In the present sample the type II valves with strand like conformation contained cells similar to those found in the cardiac conduction system. The presence of cells of the conduction system of the heart in this type of Thebesian valve makes the risk of possible complications during cannulation higher as they could be a source of arrhythmias stemming from the ability of these cells to depolarise spontaneously. This latter hypothesis requires further scrutiny.

This study examined post-mortem heart tissue, and so observation cannot be directly generalisable to in vivo human hearts. The dynamic nature of the valve was not able to be observed thus it is hard to precisely determine how the variability in the morphology of the Thebesian valve affects its function. Nonetheless, the findings presented in this investigation are important to further understand the anatomy of this region and how the various morphologies can affect invasive cardiac procedures.

\section{CONCLUSIONS}

This study highlights the variability in the structure of the CS ostium and suggests that a clear understanding of the topography of this region is important for electrophysiologists. The type of Thebesian valve observed can affect the success of invasive procedures. The fold-like Thebesian valve (type V) can complicate cannulation of the CS by obstructing access to the sinus. Similarly the atypical histological structure of the chord-like valve (type II) may complicate invasive cardiac procedures as the valve possess cells with conductive abilities and so the potential to induce arrhythmias. Thus a detailed knowledge of the CS region and understanding the potential implications of the morphology of this area may be pivotal in helping to plan and adapt procedural strategies during invasive cardiac procedures. 


\section{ACKNOWLEDGEMENTS}

The authors would like to thank greatly to Jan Kołodziej, MD for help in collecting the material for research. We would like to appreciate contribution of Mr Jacenty Urbaniak to the visual side of this article.

\section{REFERENCES}

1. Anderson R, Yanni J, Boyett M, Chandler N, Dobrzynski H (2009) The anatomy of the cardiac conduction system. Clin Anat, 22: 99-112.

2. Anh DJ, Eversull CS, Chen HA, Mofrad P, Mourlas NJ, Mead RH, Zei PC, Hsia HH, Wang PJ, Al-Ahmad A (2008) Characterization of human coronary sinus valves by direct visualization during biventricular pacemaker implantation. Pacing Clin Electrophysiol, 1: 78-82.

3. Cao M, Chang P, Garon B, Shinbane J (2012) Cardiac resynchronization therapy: double cannulation approach to coronary venous lead placement via a prominent Thebesian valve. PACE, 36: 70-73.

4. Cozma D, Mornos C (2006) Electrophysiological and echocardiographics parameters predisposing to atrial fibrillation in patients with structurally normal heart. Kardiol Pol, 64: 143-150.

5. de Oliveira IM, Scanavacca MI, Correia AT, Sosa EA, Aiello VD (2007) Anatomic relations of the Marshall vein: importance for catheterization of the coronary sinus in ablation procedures. Europace, 10: 915-919.

6. Habib A, Lachman N, Christensen KN, Asirvatham SJ (2009) The anatomy of the coronary sinus venous system for cardiac electrophysiologist. Europace, 11: 15-21.

7. Karaca M, Bilge O, Dinckal M, Ucerler H (2005) The anatomic barriers In the coronary sinus: implcations for clinical procedures. J Intern Cardiol Electrophysiol, 14: 89-94.
8. Katti K, Patil NP (2012) The Thebesian valve: gatekeeper to the coronary sinus. Clin Anat, 25: 379-385.

9. Kautzner J (2009) Thebesian valve: the guard dog of the coronary sinus? Europace, 11: 1136-1137.

10. Lewicka-Nowak E, Sterliński M, Dąbrowska-Kugacka A, Maciąg A (2005) Problemy i niepowodzenia związane ze stosowaniem stymulacji dwukomorowej u pacjentów z zaawansowaną niewydolnością serca. Cardiol J, 5: 343-348.

11. Mak GS, Hill AJ, Moisiuc F, Krishnan SC (2009) Variations in Thebesian valve anatomy and coronary sinus ostium: implications for invasive electrophysiology procedures. Europace, 9: 1136-1137.

12. Moss AJ, Hall WJ, Cannom DS, Klein H, Brown MW, Daubert JP, Estes NA 3rd, Foster E, Greenberg H, Higgins SL, Pfeffer MA, Solomon SD, Gilber D, Zareba W (2009) Cardiac resynchronization therapy for the prevention of heart-failure events. N Engl J Med, 361: 1329-1338.

13. Oginosawa $Y$, Abe $H$, Nakashima $Y$ (2006) Prevalence of venous anatomic variants and occlusion among patients undergoing implantation of transvenous lead. Pacing Clin Electrophysiol, 28: 425-428.

14. Parikh GM, Halleran SM, Bharati S, Trohman RG (2011) Successful percutaneous cardiac resynchronization despite an occlusive Thebesian valve. Pediatr Card, 32: 1223-1227.

15. Pejkovic B, Krajnc I, Anderhuber F, Kosutic D (2008) Anatomical variations of the coronary sinus ostium area of the human heart. J Int Med Res, 2: 314-321.

16. Singh JP, Houser S, Heist K, Ruskin J (2005) The coronary venous anatomy. J Am Coll Cardiol, 1: 68-74.

17. Tang ASL, Wells GA, Talajic M, Arnold MO, Sheldon R, Connolly S, Hohnloser SH, Nichol G, Birnie DH, Sapp JL, Yee R, Healey JS, Rouleau JL (2010) Cardiac resynchronization therapy for mild-moderate heart failure. $\mathrm{N}$ Engl J Med, 363: 2385-2395. 